\title{
Using Stainless Steel and Titanium Alloy in Charcot Foot Reconstruction. FEA Simulation and Clinical Case
}

\author{
MARIUS VASILESCU ${ }^{1}$, IULIAN ANTONIAC ${ }^{1}$, DAN IOAN STOIA ${ }^{2 *}$, DAN LAPTOIU ${ }^{3}$, \\ ANDREEA STOIA ${ }^{2}$, COSMINA VIGARU ${ }^{*}$, SEBASTIAN GRADINARU ${ }^{4}$ \\ ${ }^{1}$ University Politehnica of Bucharest, Department of Metallic Materials Science, Physical Metallurgy, 313 Splaiul \\ Independentei, J Building, 060042 Bucharest, Romania \\ ${ }^{2}$ Politehnica University of Timișoara, Faculty of Mechanical Engineering, Department of Mechanics and Strength of \\ Materials, 1 Mihai Viteazul Str., 300222, Timisoara, Romania \\ ${ }^{3}$ Colentina Clinical Hospital, Orthopedic Clinic 2, 19-21 Soseaua Ștefan cel Mare, 020125, Bucharest, Romania \\ ${ }^{4}$ University of Medicine and Pharmacy Carol Davila Bucharest, Faculty of General Medicine, 8 Eroiii Sanitari Str.,050474, \\ Bucharest, Romania
}

\begin{abstract}
The aim of the study was to simulate a clinical case of Charcot foot reconstruction, using finite element analysis (FEA). Our work starts from a clinical failure case of Charcot arthrodesis, were one stainless steel Midfoot Fusion Bolt $(M B F)$ prematurely failed. Starting from CT images a $3 D$ model of the foot was reconstructed and together with the intramedullary bolts a virtual assembly was build. In addition, a second 3D model containing $3 \mathrm{MBF}$ screws and one titanium locking compression plate (LCP) was constructed. The loading conditions used in FEA were extracted based on foot biomechanics according to the gait phases. The results are showing the critical sections of the bolts and also the stress shielding effect that appears on the bolts when the plate is used as supplementary fixation element. By comparing the stress values on bolts and plate with the yield strength of stainless steel and titanium alloy that are regularly used for manufacturing these implants, a valid reconstruction solution was found. This result can help surgeons in establishing the proper bolt insertion and plate positioning for minimizing the implant failure risk.
\end{abstract}

Keywords: Charcot arthrodesis, titanium alloy, FEA, gait phases, foot reconstruction

\section{Introduction}

Charcot osteo-neuroarthropathy $(\mathrm{CN})$ is a severe foot and ankle pathology associated in diabetic patients. The detailed aetiology of $\mathrm{CN}$ is still poorly understood, but important factors that determine this condition are repeated overloading (neuropathy foot injury), local between osteoblasts and osteoclasts [1]. Retrospective studies on patients with diabetic Charcot osteoarthropathy (CA) on the off-loading effect was conducted by Tomas M. Christensen et.al. They involve in the study 56 patients and consider an off-loading time of $141 \pm 21$ days. At the end of the period, no significant influence of the off-loading period on the recurrence of CA was determined [2]. An extensive study on patients with osteo-neuroarthropathy $(\mathrm{CN})$ that exhibit severe instability and deformity of the foot was reported by Martinus Richter et.al. They use Midfoot Fusion Bolt (MFB) implants for realigning and fixation. The results of the study underline stable fixation with MFB as a valuable treatment option for $\mathrm{CN}$. Also, the study recommends the use of minimum two bolts for avoiding the recurrent deformity of the foot [3]. A study on two patients that underwent tibiocalcaneal arthrodesis using retrograde intramedullary technique by Expert Tibial Nail was reported by Oesman et.al. A good satisfaction score relying on good stability of the foot was achieved for both patients. The ETN system was proven to be a good option for ankle joint surgery [4], generating minimal soft tissue violation and producing adequate deformity correction. Also, less postoperative fusion time is associated with these intramedullary nails.

*email:dan.stoia@upt.ro,cosmina.vigaru@upt.ro 
The invasive surgical correction of the Charcot foot is typically resulted in non-anatomic correction, due to the midfoot osteotomy techniques that implies removal of the altered bone and internal screw-plating fixation. This complication can be avoided by using the minimally invasive techniques like Midfoot Fusion Bolt technique [5]. The performance of an implant is dramatically influenced by a series of factors like: failure of the surgical procedure; overloading due to accidents or intense physical activity; the interaction between body and implant; the materials used in all mechanical parts; the design of the mechanical parts; the screw configuration and insertion angles; the noncompliance of the patient to the medical prescriptions. [6-9]. Because of the loading complexity that an implant undergoes inside the body, an estimation of the implant life and capacity to withstand the various loading scenarios that may occur during lifetime is very important. The FEM simulation of biomechanical behavior of bone-implant structure is a great help in this manner and was used along the time by many authors on various implantation sites [10-17]. Cheung and Zhang developed an anatomical 3D ankle-foot model consisting of 28 separate bone segments, 72 ligaments, plantar fascia, and a soft tissue boundary. They reported the first 3D FE simulation considered detailed anatomical structures ankle-foot movements, joined soil-foot contacts as well as non-linear properties of biomaterials [18]. For human musculoskeletal modeling, the challenge remains to produce geometric, cinematic and mechanically accurate models that can be used in fundamental analysis, such as simulation of biomechanical failures and prediction $[19,20]$.

\section{Material and methods}

\subsection{Charcot reconstruction technique}

The surgical principle of off-loading involves the reduction of any skin pressure by reducing any deformation of the foot in order to treat and prevent ulcers. [21] After correction of bone deformity, several Charcot foot surgical techniques are used, but there is no consensus on optimal fixation because none of the techniques proved to be superior as clinical outcomes. Recent research into internal osteosynthesis - locked plate technology and intramedullary bolts super constructs became encouraging choices in diabetic foot surgery [22]. In the figure 1a, typical CT appearance of Charcot foot with medial-foot fragmentation and rocker bottom deformity are presented for a 71 years old diabetic patient. The "rocker-bottom" aspect is defined as the progressive deformation of the midfoot from diabetic neuropathy, deformity accompanied by instability and, frequently, plantar ulcer. Arthrodesis in these patients is a rescue procedure that can prevent ulceration, associated infection and thus prevent amputation. Indicative measurements for preoperative bone resection planning are presented in the figure $1 \mathrm{~b}$.

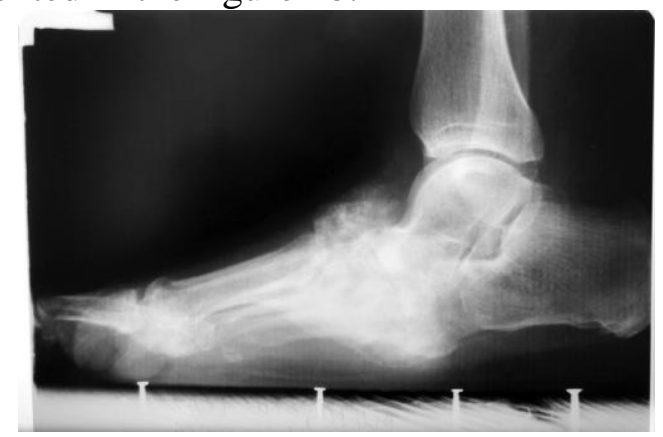

a)

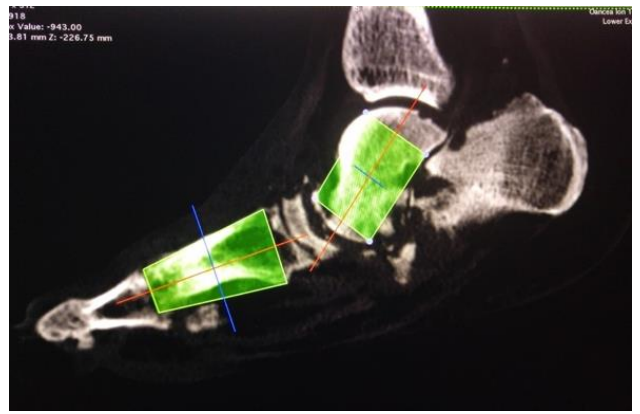

b)

Figure 1. Typical appearance of Charcot foot with medial-foot fragmentation and rocker bottom deformity

Surgical off-loading is a technique particularly indicated in the chronic phase of Charcot's foot. Due to bone disorder, local vascular and nutritional status, the surgical reconstruction of the midfoot deformity is often complicated [23,24]. The theory of super-construct [25] in the Charcot foot is defined by four technical factors: arthrodesis is extended to adjacent, unaffected joints to improve 
fixation; osteotomy of the midfoot in the root with the plantar and medial base is performed for a proper reduction of stress-free deformation on soft tissues; the use of the strongest osteosynthesis implant that can be covered by the soft tissue envelope; applying the implant in the best biomechanical position. For super-construct reconstruction several techniques are discussed in the orthopedic literature, most important being: plantar plates, blocked plates and intramedullary bolts. Current study starts from a 3D model of the Charcot foot, reconstructed from patient's computer tomography (CT scan) and aims explaining several particular scenarios observed in current clinical practice with a special attention to failure cases [26].

\subsection{D reconstruction and modelling of the implanted foot}

The 3D geometric reconstruction is based on DICOM images obtained by CT scanning and was performed using the MIMICS 10.01 (Materialise) software. Due to the complex anatomy of the Charcot foot, modified by the mediotarsian subluxation, two color masks were selectively applied to the data images: one for the tibia, talus and calcaneus, and the other for the bones of the forefoot (Figure 2).

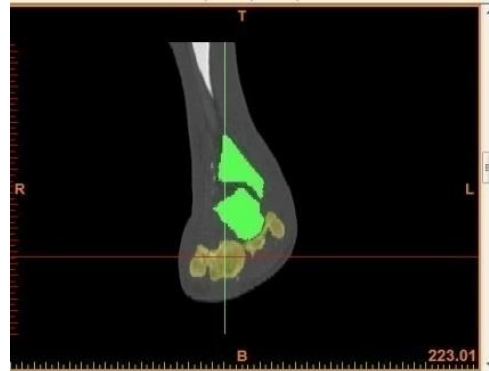

a)

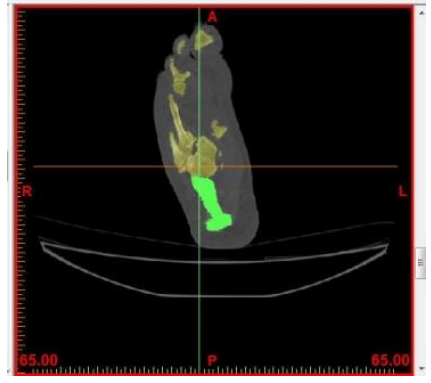

b)



c)

Figure 2. DICOM images and color mask overlapped for 3D reconstruction of the foot:

a) - frontal view; b) - transversal view; c) - lateral view

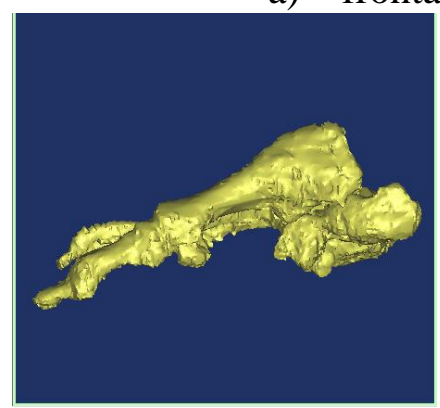

a)

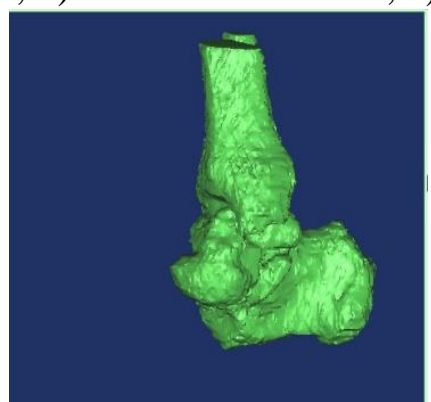

b)

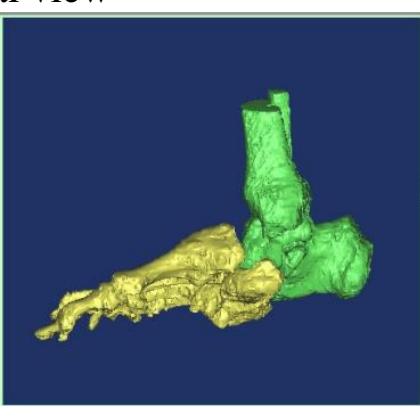

c)

Figure 3. Primary reconstruction of the foot: $a$ ) - forefoot; $b$ - backfoot;

c) - foot assembly

The purpose of this procedure is to rebuild an anatomical area from CT data and validate the threedimensional physical model of the bone structure of the Charcot foot not only for pre-operative planning, but also for the numerical analysis of some special clinical situations. This is related to the analysis of several clinical failures associated with the rupture of specialized implants such as Midfoot Fusion Bolts (MFB Synthes @).

The colored masks were then transformed into separate volumes and exported in the form of point clouds. It can be seen (Figure 3) the reduced quality of the reconstructed volumes. This is due to the way the reconstruction program performs interpolation - both in the image plane and between successive slides, even if the capture of the image data was performed according to published protocols (1 mm scans slice, no tilt etc.) [27]. 
In order to be used in numerical analysis, rebuilt volumes must undergo a surface integrity verification process, whereby self-interference areas, eventual discontinuities, or areas with very sharp peaks that are neither natural nor adapted to the process of simulation. Geometric integrity and volume refinement were performed using Geomagic STUDIO 9. Figure 4 shows some types of defects encountered in the tibia and tibia area. The presence of these defects makes numerical analysis impossible due to the impossibility of generating the bulk mesh. As a result, these were remedied, partially automatic, partially manual, after consulting with the orthopedic surgeon in order to validate the anatomical reconstruction.

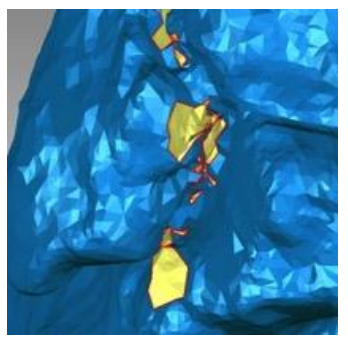

a)

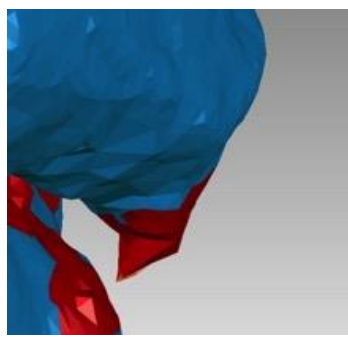

b)



c)

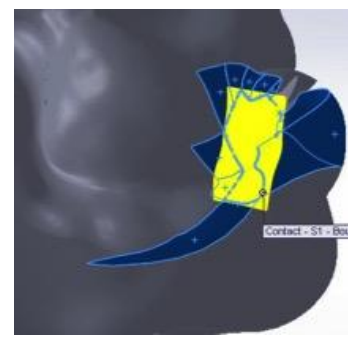

d)

Figure 4. Types of defects after primary reconstruction: a) - Mesh gaps;

b) - sharp surfaces; c) - self-intersected surfaces; d) - gap patching

After surface integrity repair operations, the geometric model was refined, increasing by 2.5 times the number of surface triangles. Thus, the resulting volumes obtained a smooth aspect, valid for the numerical analysis (Figure 5) [28]. Because every surface smoothness will lead to losing some geometrical aspects and dimension, a balance must be found between the surface refinement and anatomical details.

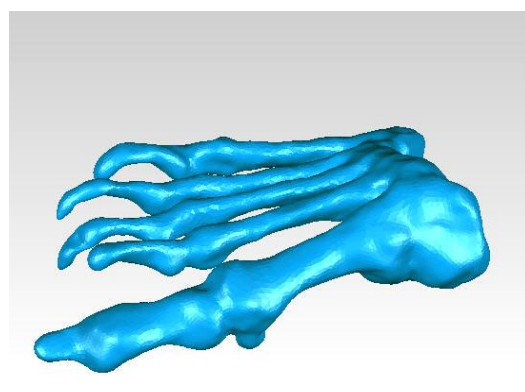

a)

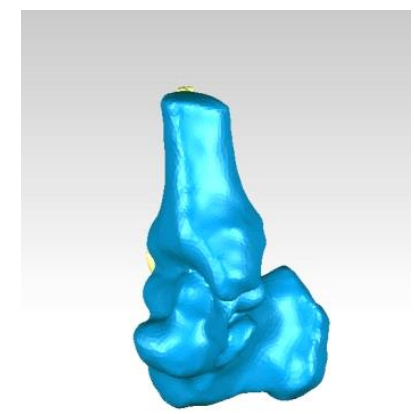

b)

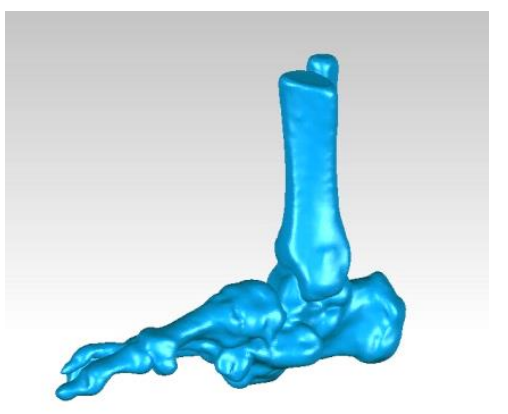

c)

Figure 5. Foot reconstruction after mesh refinement: a) - forefoot; b) - backfoot; c) - foot assembly

The mechanical components (bolts and plate) were modeled using SOLIDWORKS 2013 (Dasault Systems). The geometrical assemblies corresponding to the two studied cases are: scenario I - fixation by means of 3 intramedullary screws; scenario II - fixation with 3 intramedullary screws and one plate. In order to achieve a valid assembly anatomic to mechanical elements, bones were geometrically processed by means of: alignment sections, longitudinal orifices and transverse apertures (Figure 6). 


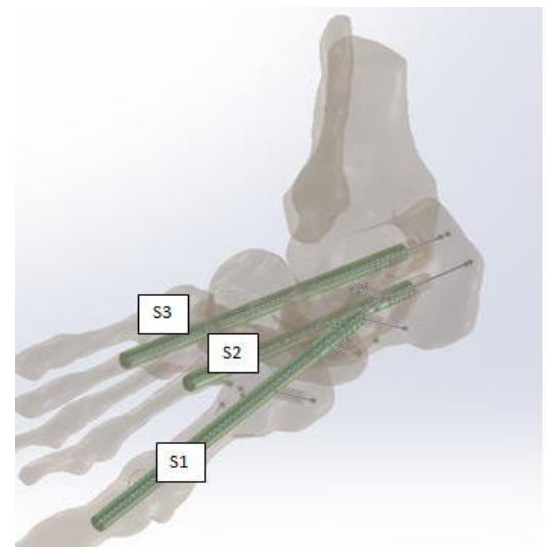

a)

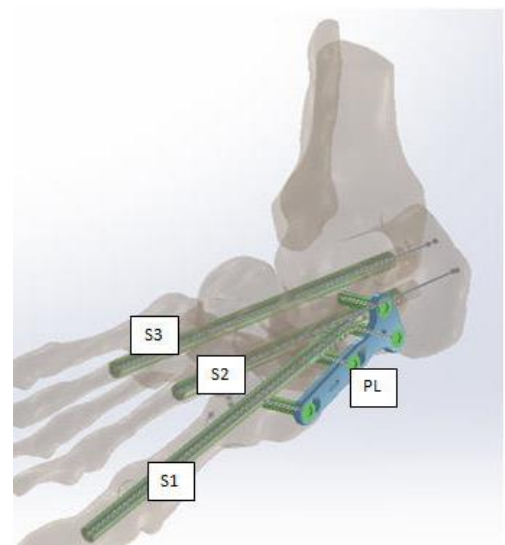

b)

Figure 6. Geometric models of the two studied scenarios:

a) - Scenario I - 3MFB implanted screws;

b) - Scenario II - 3 MFB implanted screws and 1 LCP

Implant modeling was done taking into account the size and conformation of the midfoot. The bone-implant model was designed such that the LCP plate with the corresponding locking screws and the MFB bolts have maximum contact in the in the distal bone and there is no interference between the implants. Also, contacts between locking screws and plate were established.

Due to complexity of the biomechanical loading at foot level, we divide our simulation in three cases, each corresponding to a gait phase as it follows: Loading response (LR); Mid stance (MS); Pre swing (PS) (Figure 7). For each of the three gait phases a particular loading and restriction conditions and surfaces of force insertion were applied. These conditions are detailed in the Table 1.
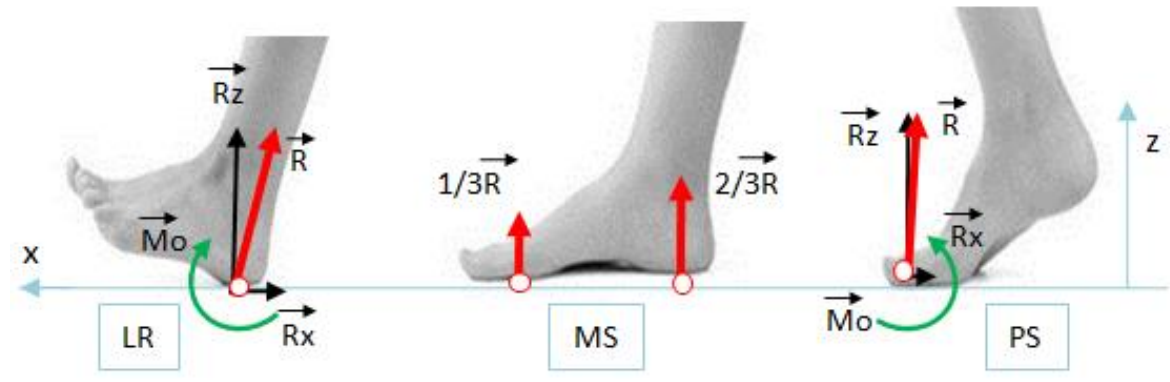

Figure 7. Ground reaction forces in main gait phases: Loading response (LR); Mid stance (MS); Pre swing (PS).

Table 1. Loadings and boundary conditions according to gait phase

\begin{tabular}{|c|c|c|c|c|c|}
\hline $\begin{array}{l}\text { Loading } \\
\text { scenarios }\end{array}$ & Gait phase & $\begin{array}{l}\text { Fixed support } \\
\text { site }\end{array}$ & Loading [N] & $\begin{array}{c}\text { Force insertion } \\
\text { site }\end{array}$ & $\begin{array}{c}\text { Stabilization } \\
\text { system }\end{array}$ \\
\hline \multirow[t]{3}{*}{ 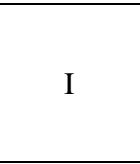 } & Pre swing & & 930 & Sesamoid & $3 \mathrm{MFB}$ \\
\hline & Mid stance & Tibial pilon & $1 / 3 \cdot 850$ and $2 / 3 \cdot 850$ & $\begin{array}{l}\text { Sesamoid and } \\
\text { Calcaneus }\end{array}$ & 3 MFB \\
\hline & Loading response & & 940 & Calcaneus & $3 \mathrm{MFB}$ \\
\hline II & Pre swing & Tibial pilon & 930 & Sesamoid & $3 \mathrm{MFB}+\mathrm{LCP}$ \\
\hline
\end{tabular}

From the measurements of human plantar pressures during walking it is known that the ground contact force in the LR and PS phases exceeds the static weight value by $9-12 \%$, while in the mid stance phase (MS) the static force value is diminished by 13 to $17 \%$. This phenomenon is caused by the accelerations and decelerations of the limbs, that together with the masses of the body segments lead to dynamical loadings. The loads were defined according to the principles of classic mechanics 
for a person weighting $85 \mathrm{Kg}$ (normal biomechanical gait data for an $85 \mathrm{~kg}$ subject walking at a cadence of $80 \mathrm{steps} / \mathrm{min}$ ) [29]. The Achilles tendon and plantar fascia were simulated in the analysis by means of two elastic elements and defined by an elastic force of $750 \mathrm{~N} / \mathrm{mm}$ [29]. The loading on the Achilles tendon was established as $75 \%$ of the total plantar stress- based on studies showing that this setting brings the closest results to the experimentally measured elements in vivo [30, 31]. The proximal ends of the tibia and fibula were set fixed during the analysis. After considering loadings and restraining of the model, the material properties were set for every individual element. So, an equivalent bone property was set for the bone elements, ligament properties for ligaments, titanium for bolts and plate, according to the Table 2 [32-36].

Table 2. Mechanical properties of materials

\begin{tabular}{|c|c|c|c|c|c|}
\hline Material / Property & $\begin{array}{c}\text { Young modulus } \\
\text { [GPa] }\end{array}$ & $\begin{array}{l}\text { Poisson } \\
\text { ratio [-] }\end{array}$ & $\begin{array}{c}\text { Density } \\
{\left[\mathrm{Kg} / \mathrm{mm}^{3}\right]}\end{array}$ & $\begin{array}{c}\text { Yield Strength } \\
{[\mathrm{MPa}]}\end{array}$ & $\begin{array}{c}\text { UTS } \\
{[\mathrm{MPa}]}\end{array}$ \\
\hline $\begin{array}{l}\text { Titanium alloy } \\
\text { (Ti-6Al-4V) }\end{array}$ & 113 & 0.36 & $4.62 * 10^{-6}$ & 880 & 950 \\
\hline $\begin{array}{c}\text { Austenitic Stainless Steel } \\
\text { (316L) }\end{array}$ & 205 & 0.28 & $7.87 * 10^{-6}$ & 170 & 485 \\
\hline $\begin{array}{l}\text { Bone (equivalent } \\
\text { properties) }\end{array}$ & $7-30$ & 0.35 & $3.81 * 10^{-6}$ & - & $80-150$ \\
\hline Ligaments & $1-2$ & 0.35 & $4.0 * 10^{-6}$ & - & $50-150$ \\
\hline
\end{tabular}

FEA was performed using the ANSYS 13.0 software and aimed to determine the stress and deformation states of the mechanical elements and bones according to the physiological loadings that corresponds to the gait phases. The simulation was applied subsequently on both scenarios. Bone elements, elastic ligaments and osteosynthesis components were discretized by constant size tetrahedral elements (Figure 8), every component containing the number of elements and nodes according to the Table 3 . The contacts of the bodies were defined in close connection to the natural contact surfaces that occurs when assembling the stabilization implants. They were defined as bonded, in order to simulate the osteointegration condition. The way of defining the contacts is very important in FEM analysis because this aspect is greatly influencing the loading transition between neighboring components (Figure 9).



a)

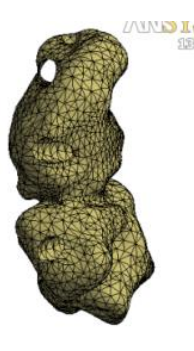

b)

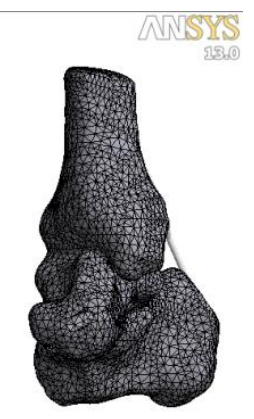

c)



d)

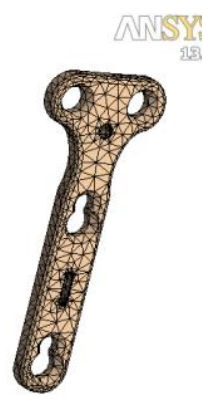

e)

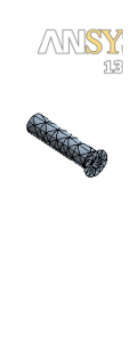

f)

Figure 8. Mesh structure of each individual components: a) - forefoot; b) - middle foot; c) - backfoot; d) - MFB bolt; e) - LCP plate; f) - plate locking screw.

Table 3. Mesh statistics for individual components

\begin{tabular}{ccc}
\hline Part name & Elements & Nodes \\
\hline LCP plate & 3422 & 6543 \\
Plate screws x4 & 297 & 637 \\
MFB-S3 & 1957 & 3866 \\
MFB-S2 & 2046 & 4065 \\
\hline
\end{tabular}




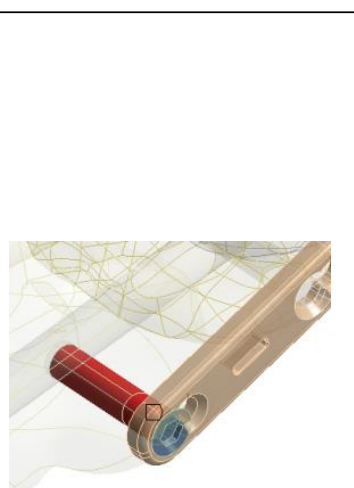

a)



b)

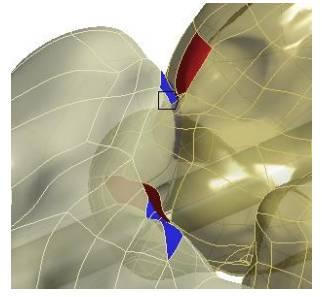

c)

$\begin{array}{cc}1864 & 3725 \\ 28050 & 49809 \\ 11477 & 20027 \\ 31100 & 52076\end{array}$

Figure 9. Contact definition between assembly elements: a) - fixation screw-plate; b) - fixation screw-bone; c) - bone to bone; d) - MFB bolt to forefoot; e) - MFB bolt to backfoot

\section{Results and discussions}

\subsection{Simulation scenario I}

The equivalent elastic stress, equivalent strain and total deformation of the structure are presented for the simulation scenario I, for the LR, MS and PS gait phases respectively (Figures 10, 11 and 12). The reaction that occurs at heel contact is transmitted through the tibio-talar joint at the level of the tibia and further to the knee. As consequence, the arthrodesis stress are reduced, and therefore the bolt screws exhibit low stress values (below $30 \mathrm{MPa}$ ).

Taking into account their allowable stress of $260 \mathrm{MPa}$, it can be stated by comparison that at the LR phase of the gait implies no risk of failure of any of the 3 MFB screws. The total displacement of the structure is reduced and is located near the calcaneus bone.

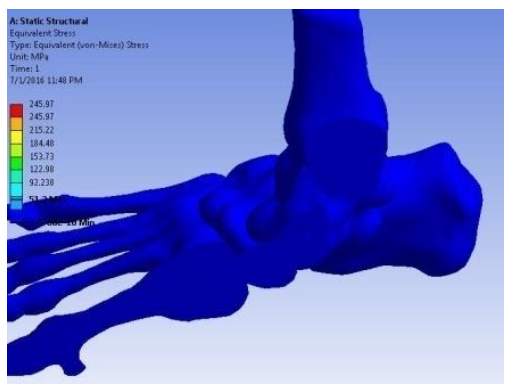

a)

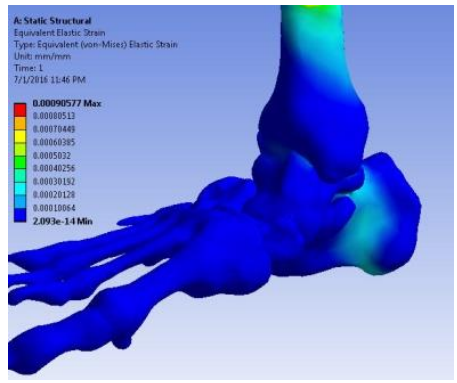

b)

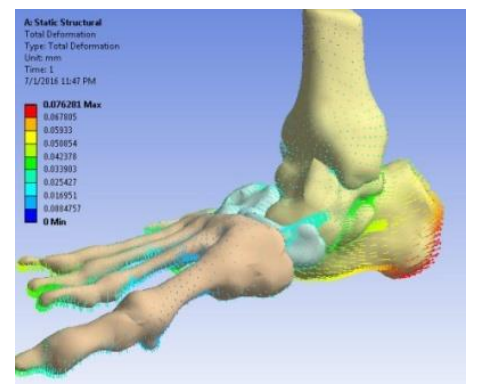

c)

Figure 10. Results of LR phase: a) - global equivalent stress; b) - global equivalent strain; c) - total deformation of the structure

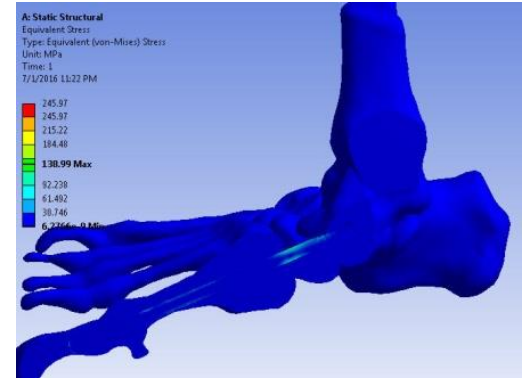

a)

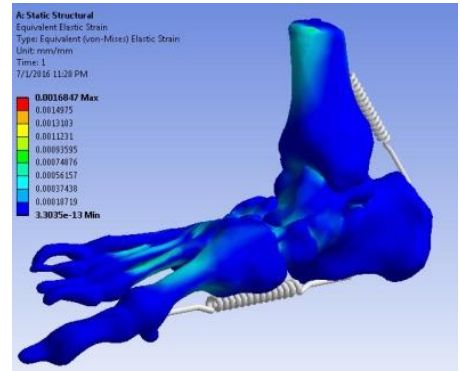

b)

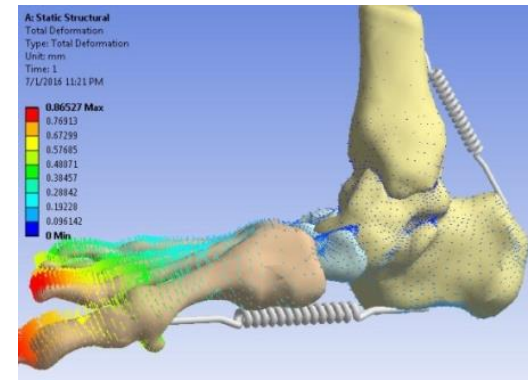

c)

Figure 11. Results of MS phase: a) - global equivalent stress; b) - global equivalent strain; c) - total deformation of the structure 


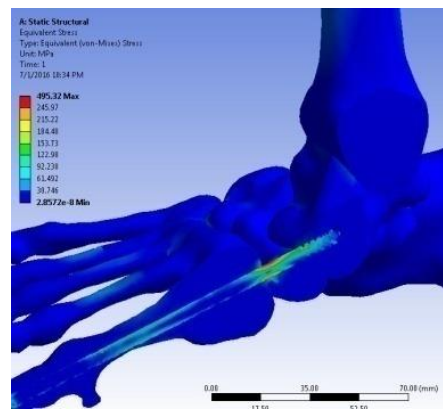

a)

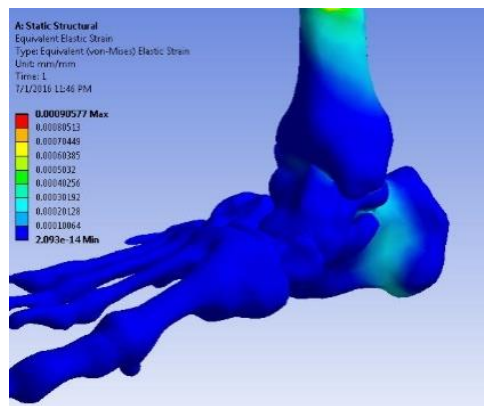

b)

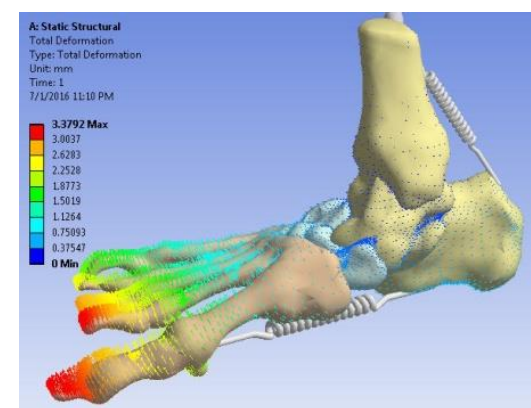

c)

Figure 12. Results of PS phase: a) - global equivalent stress; b) - global equivalent strain; c) - total deformation of the structure

The MS phase corresponds to the medial support situation, when the biomechanical axis of the foot and ankle is vertical. In this case, a distributed force was applied 1/3 on the sesamoid bone while $2 / 3$ of the force on the calcaneus. The results indicate an increase in the stresses at the level of the arthrodesis plane, respectively the occurrence of a significant stress on the screw S1 (fusion of metatarso-cuniform joints - naviculo-cuniform - talo-navicular) of approx. $130 \mathrm{MPa}$. The displacements of the structure appear this time at the forefoot, due to the bony structure more supple than the backfoot.

The PS phase simulates the propulsion phase of the gait cycle in which the contact with the ground is made only by the forefoot (sesamoid area). From motion dynamics, this phase is characterized by higher loadings of $9-12 \%$ of the patient's own weight. In this condition, the stress values recorded for S1 exceeds the admissible stress: $\sigma_{\max }=450 \mathrm{MPa}>\sigma_{\mathrm{a}}=250 \mathrm{MPa}$. High stresses are also recorded for the $\mathrm{S} 2$ bolt, meaning that the whole reconstruction is at potential risk. The yielding values of stress are recorded for S1 in the vicinity of the naviculo-cuneiform plane and at the calcaneo-cuboid level for S2.

The surface stresses were sampled on the circumference of the bolts (Figure 13 a) using 15 constant points, in the most stresses section for every bolt. Using these values and the yield strength values for titanium and steel and also the ultimate tensile stress (UTS) for bone, stress variations were graphical depicted (Figure 13, b-d). The most exposed bolt is S1, followed by S2 and S3, with maximum stress levels of 450, 200 or $120 \mathrm{MPa}$ respectively, regardless the type of loading. The differences that occurs between them are due to the anatomy of the foot as well as the way the weight distribution. The asymmetric stresses to the axis of symmetry of the bolts are recorded due to the bending stresses, which lead to the conclusion that the dominant loading is bending type. Also, an important observation is that PS gait phase is the single phase that produce stresses in bolts that exhibit the yielding points of the constituent materials.

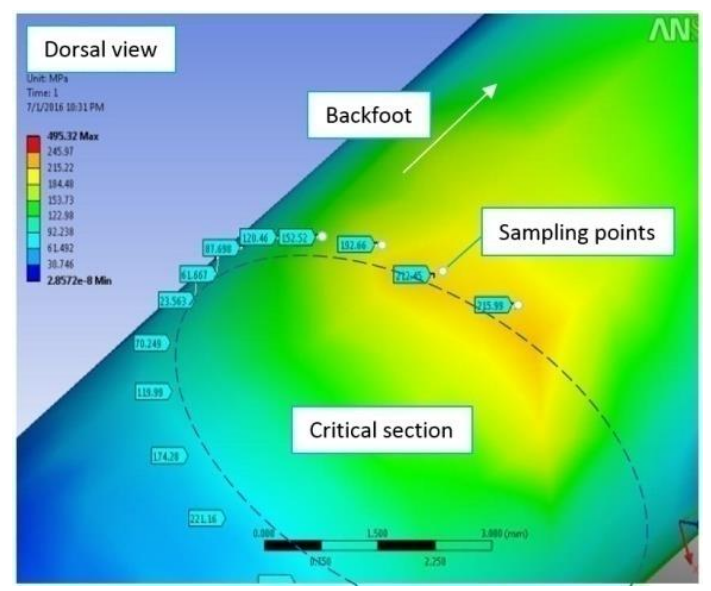

a)

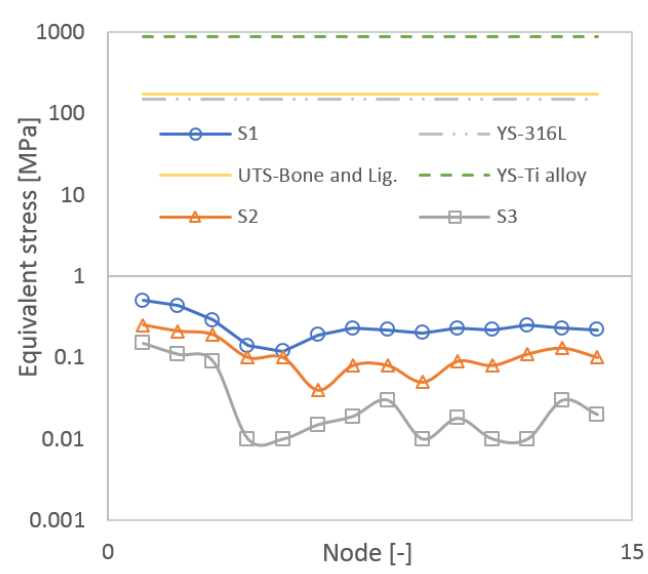

b) 


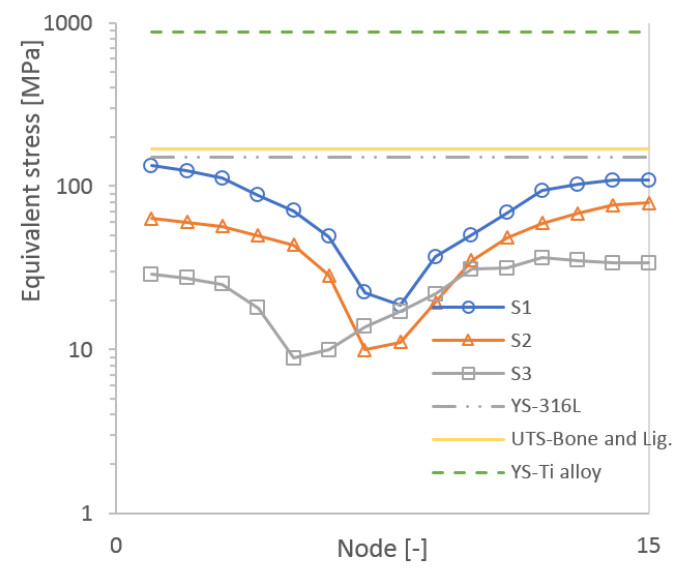

c)

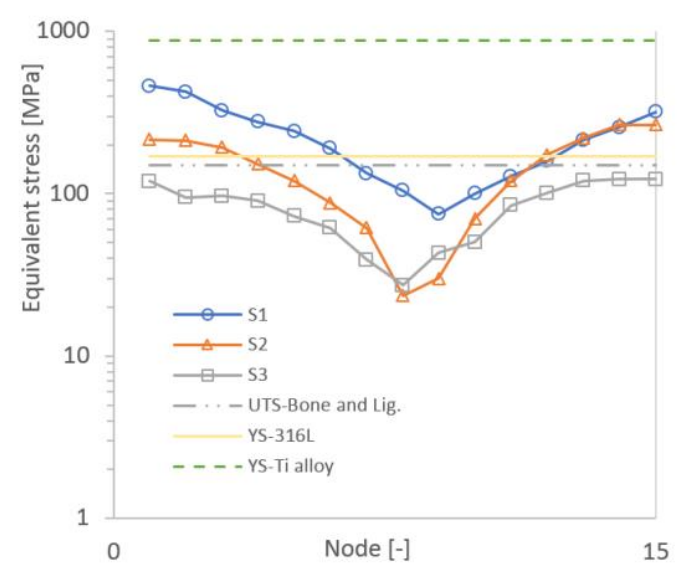

d)

Figure 13. Stress sampling points and graphical representation: a) - stress sampling section of the MFB; b) - Stress variation in S1, S2 and S3, according to LR phase;

c) - Stress variation in S1, S2 and S3, according to MS phase;

d) - Stress variation in S1, S2 and S3, according to PS phase

\subsection{Simulation scenario II}

The second scenario simulates a reconstruction using 3 intramedullary bolts and one LCP for supplementary stabilization and bone stress shielding. The plate was immobilized in the bone structure of the foot by means of 4 fixing screws.

This analysis was carried out only in the case of PO loading, as it was observed from the first simulation that it is the only situation where the stresses in the implanted elements exceed the allowable stresses of the constituent materials. Figure 14 shows the overall stress distribution and deformation of the structure in the new geometric condition. It can be noticed how the LCP is contributing to the load transfer in the lateral side of the foot.

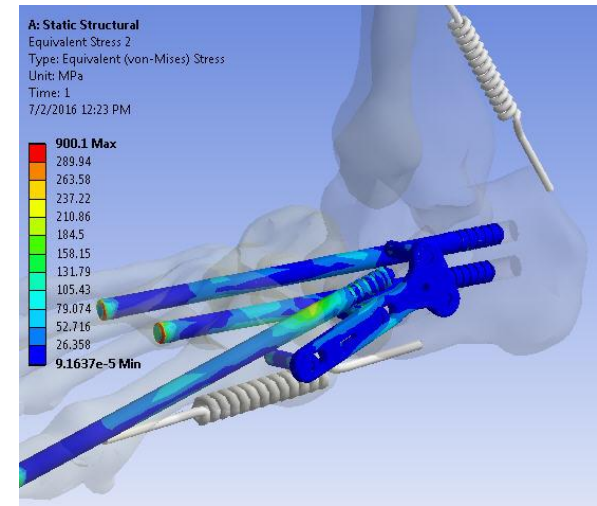

a)



b)

Figure 14. Stress a) and deformation state b) of the whole model (scenario II) in PS phase

By isolating every individual component and presenting the stress values on each (Figure 15 a-d), a significant reduction in S1 bolt can be observed, which decrease now from a maximum of $450 \mathrm{MPa}$ reached in scenario I to a value of $225 \mathrm{MPa}$, which is in the safe zone. In conclusion, the additional insertion of LCP in the lateral foot side, contribute to the prevention of extreme stresses that may otherwise lead to plastic deformation and then to fatigue failing. 


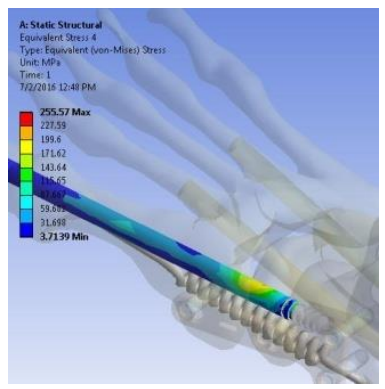

a)

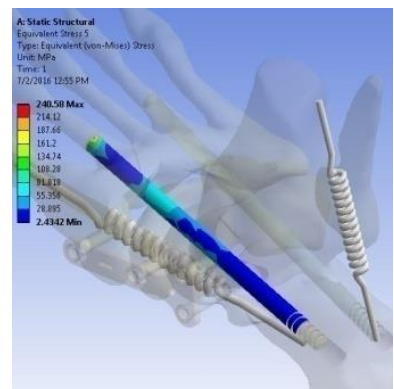

b)



c)

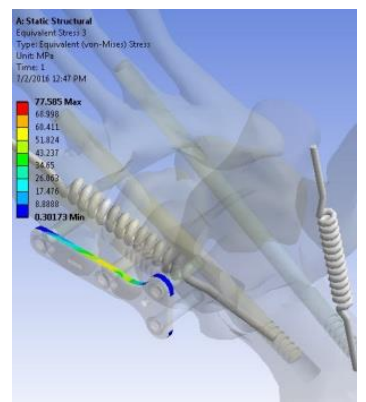

d)

Figure 15. Stresses in the individual elements of the second model (scenario II) in PS phase: a) - S1 bolt; b) - S2 bolt; c) - S3 bolt; d) - LCP.

The figure 16 depicts the stress in S1 bolt in both loading scenarios. A 130\% reduction of the stress values is recorded for the must loaded section of the $\mathrm{S} 1$. The graph also presents the relative uniform stress distribution of the LCP, which is responsible for bolts stress reduction. None of the components in this case are exhibiting the allowable strength. The plate used in this type of bone reconstruction can therefore make the difference between the success and failure of intramedullary implants.

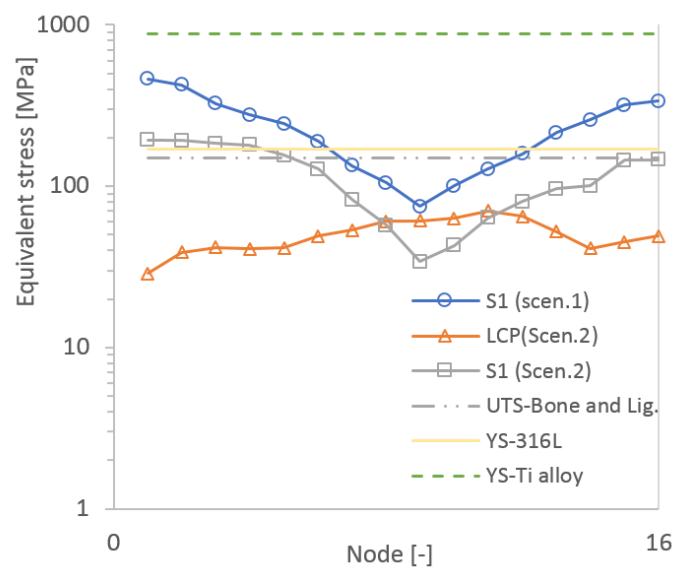

Figure 16. Stress variation in the highly loaded sections for scenario II and PS phase

\subsection{Clinical case}

The simulations confirm a clinical case of MFB failure (Figure 17). The arthrodesis evolution of the reconstructed leg that was not modified by the Charcot arthropathy with a negative Meary angle (lateral tars - prim metatarsian) lead to a bolt failure. The values below 27 degrees of this angle are accompanied by exponential increase in stresses at the level of the mediotarsian area. A solution in stress shielding of MFB that also lead to a stiffer osteosynthesis is the usage of LCP in addition to the primary reconstruction (Figure 18).

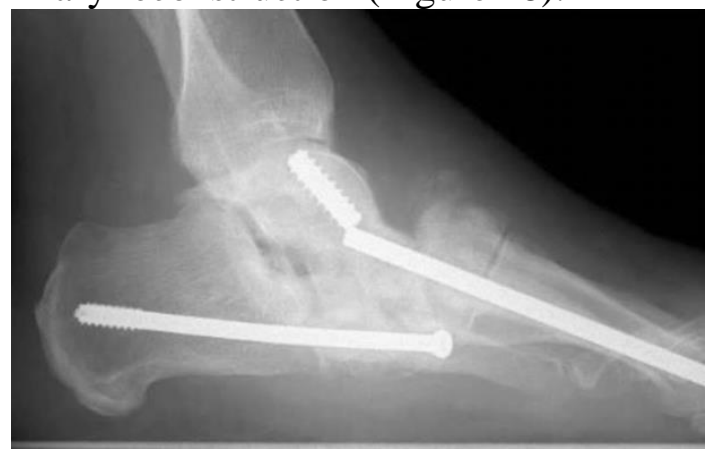

Figure 17. Radiological image at 6 months with breakage of one MFB - Clinical case

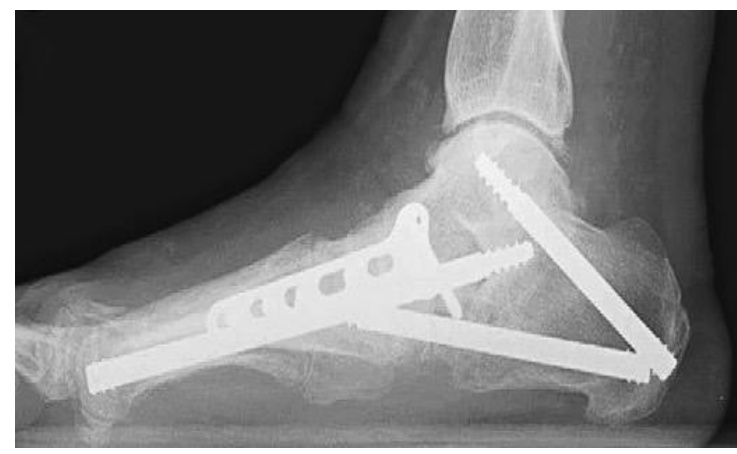

Figure 18. Arthrodesis by mixed use of MFB intramedullary bolts and one medial placed LCP 


\section{Conclusions}

From perspective of gait biomechanics, the arthrodesis is the most strongly loaded section during the propuls ion phase of walking (pre-swing).

Directly connected with patient's daily activities and its own body weight, a Charcot reconstruction using $3 \mathrm{MFB}$ of $6.5 \mathrm{~mm}$ can be insufficient, at least for the bolt that crosses the medial taper bone.

By medial or lateral placement of an additional LCP, extreme stresses in MFB can be prevented, reducing therefore the risk of implant failure.

The failure of the MFB in a section inside the talus (Figure 17) is due to the lever effect generated by through the bolt. This effect is the result of two concomitant phenomena: the bending loading of the bolt and the lack of bone material in the surrounding area of the thread.

\section{References}

1.LEE C. ROGERS et.al. The Charcot Foot in Diabetes, Diabetes Care, Vol. 34, 2011, https://care.diabetesjournals.org/content/34/9/2123.full-text.pdf

2.TOMAS M. CHRISTENSEN, BIRTHE GADE-RASMUSSEN, LIS W. PEDERSEN, EVA HOMMEL, PER E. HOLSTEIN, OLE L. SVENDSEN, Duration of off-loading and recurrence rate in Charcot osteo-arthropathy treated with less restrictive regimen with removable walker, Journal of Diabetes and its Complications, Volume 26, Issue 5, 2012, 430-434

3.RICHTER, MARTINUS \& MITTLMEIER, THOMAS \& RAMMELT, STEFAN \& AGREN, PERHENRIK \& HAHN, SARAH \& ESCHLER, ANICA. Intramedullary Fixation in Severe Charcot Osteo-Neuroarthropathy with Foot Deformity Results in Adequate Correction without Loss of Correction - Results from a Multi-centre Study. Foot and Ankle Surgery, 21 (2015) 269-276.

4.OESMAN, I. \& ASDI, A.R.B.. (2019). Calcaneotalotibial Arthrodesis By Retrograde Intramedullary Nailing Using Expert Tibia Nail for Charcot Osteoneuropathy of the Foot: A Case Series. International Journal of Surgery Case Reports 57 (2019) 9-14

5.BOTEZATU I, LAPTOIU D, Minimally invasive surgery of diabetic foot - review of current techniques, Journal of Medicine and Life Vol. 9, Issue 3, July-September 2016, pp.249-254

6.DEEN, K.M.; FAROOQ, A.; SADIQUI, N.A. Diagnosing the cause of dynamic compression plate premature failure. Engineering Failure Analysis, 2013, 34, 350-357.

7.WANG, Z.-Y.; WANG, Q.-Y.; CAO, M. Experimental Study on Fatigue Behaviour of Shot Peened Open- Hole Steel Plates. Materials 2017, 10, 996.

8.WANG, W.; YUAN, H.; LI, X.; SHI, P. Stress Concentration and Damage Factor Due to Central Elliptical Hole in Functionally Graded Panels Subjected to Uniform Tensile Traction. Materials 2019, 12, 422.

9.CIRSTOIU, M.; CIRSTOIU, C.; ANTONIAC, I.V. et al., Levonorgestrel-releasing intrauterine systems: device design, biomaterials, mechanism of action and surgical technique, MatPlast, 52 (2) (2015), pp. 258-262

10.MARINESCU, R.; ANTONIAC, V.I.; STOIA, D.I.; LAPTOIU, D.C. Clavicle anatomical osteosynthesis plate breakage-failure analysis report based on patient morphological parameters. Rom J MorpholEmbryol, 2017, 58(2), 593-598.

11.ANTONIAC, I.V.; STOIA, D.I.; GHIBAN, B.; TECU, C.; MICULESCU, F.; VIGARU, C.; SACELEANU, V. Failure Analysis of a Humeral Shaft Locking Compression Plate-Surface Investigation and Simulation by Finite Element Method. Materials 2019, 12, 1128.

12.ZHANG, Y.K.; WEI, H.W.; LIN, K.P.; CHEN, W.C.; TSAI, C.L.; LIN, K.J. Biomechanical effect of the configuration of screw hole style on locking plate fixation in proximal humerus fracture with a simulated gap: A finite element analysis. Injury, Int. J. Care Injured, 2016, 47, 1191-1195.

13.BOYER, R.; WELSCH, G.; COLLINGS, E.W. Materials Properties Handbook: Titanium Alloys, ASM International, Materials Park, OH, 1994; pp. 1169, 978-0-87170-481-8.

14.HAMANDI, F.; LAUGHLIN, R.; GOSWAMI, T. Failure Analysis of PHILOS Plate Construct Used for Pantalar Arthrodesis Paper II-Screws and FEM Simulations. Metals 2018, 8, 279. 
15.TARNITA, D.; BOBORELU, C.; POPA, D.; TARNITA, C.; RUSU, L. The three-dimensional modeling of the complex virtual human elbow joint. Rom J MorpholEmbryol, 2010, 51(3), 489-95.

16.DAWOD, N., FLORESCU, A., ANTONIAC, I.V., STOIA, D.I., HANCU, V., BICLESANU, F.C. The FEA Study of the Biomecanic Behavior of Canine Reconstructed with Composite Resin, Rev.Chim, No. 7, 2019, 2456-2462.

17.ALMASI, A., ANTONIAC, I., FOCSANEANU, S., MANOLE, M., CIOCOIU, R., TRANTE, O., EARAR, K., SACELEANU, A., PORUMB, A., RATIU, C., Design Improvement of Y-TZP Three Unit Bridges by Predicted Stress Concentration Using FEA and Experimental Failure Modes after Three Point Bending Test, Rev.Chim, No. 1, 2019, 336-342.

18.CHEUNG JT, ZHANG M, 2008. Parametrical design of pressure-relieving foot orthoses using statistical-based finite element method. Med Eng Phys.30, 269-277

19.PENROSE JM, HOLT GM, BEAUGONIN M, HOSE DR, 2002. Development of an accurate three-dimensional finite element knee model. Comput Methods Biomech Biomed Eng. 5, 291-300.

20.ANTONIAC, I.; NEGRUSOIU, M.; MARDARE, M.; SOCOLIUC, C.; ZAZGYVA, A.; NICULESCU, M. Adverse local tissue reaction after 2 revision hip replacements for ceramic liner fracture: A case report. Medicine 2017, 96.

21.FRYKBERG, R.G., BEVILACQUA, N.J., HABERSHAW, G. Surgical off-loading of the diabetic foot, Journal of Vascular Surgery, 52 (12S), 44-58, 2010

22.ASSAL M, RAY A, STERN R. Realignment and extended fusion with use of a medial column screw for midfoot deformities secondary to diabetic neuropathy. Surgical technique. J Bone Joint Surg Am. 2010 Mar;92 Suppl 1

23.DUMITRESCU, D.; SAVLOVSCHI, C.; BORCAN, R. et al., Clinical case - voluminous diaphragmatic hernia - surgically acute abdomen: diagnostic and therapeutical challenges Chirurgia, 106 (5) (2011), pp. 657-660

24.MAVRODIN, C.I.; PARIZA, G.; ION, D.; ANTONIAC, V.I. Abdominal compartment syndrome - a major complication of large incisional hernia surgery. Chirurgia 2013, 108, 414-417.

25.SAMMARCO VJ, SAMMARCO GJ, WALKER EW JR, GUIAO RP. Midtarsal arthrodesis in the treatment of Charcot midfoot arthropathy: surgical technique. J Bone Joint Surg Am. 2010;92 Suppl. 1 Pt 1:1-19.

26.SAMMARCO VJ. Superconstructs in the treatment of charcot foot deformity: plantar plating, locked plating, and axial screw fixation. Foot Ankle Clin. 2009 Sep;14(3):393-407

27.MAHER, M. M., KALRA, M. K., SAHANI, D. V., PERUMPILliCHIRA, J. J., RIZZO, S., SAINI, S., \& MUELLER, P. R. (2004). Techniques, Clinical Applications and Limitations of 3D Reconstruction in CT of the Abdomen. Korean Journal of Radiology, 5(1), 55-67. http://doi.org/10.3348/kjr.2004.5.1.55

28.GEFEN A, MEGIDO-RAVID M, ITZCHAK Y, ARCAN M, 2000. Biomechanical analysis of the three-dimensional foot structure during gait: a basic tool for clinical applications. J Biomechan Eng. 122,630-639

29.SUP F, VAROL HA, MITCHELL J, WITHROW TJ, GOLDFARB M. Preliminary Evaluations of a Self-Contained Anthropomorphic Transfemoral Prosthesis. IEEE ASME Trans Mechatron. 2009;14(6):667-676

30.WANG, X.; NYMAN, J. S.; DONG X.; LENG, H.; REYES, M. Mechanical Behavior of Bone. In Fundamental Biomechanics in Bone Tissue Engineering; Morgan\& Claypool Publishers, UK, 2010; pp. 75-108, 9781608451708

31.CHEUNG J.T.M., ZHANG M., AN K.N., Effect of Achilles tendon loading on plantar fascia tension in the standing foot, Clinical Biomechanics, 2006, Vol. 21, 194-203.

32.MARTIN R.B., BURR D.B., SHARKEY N.A., FYHRIE D.P. (2015) Mechanical Properties of Ligament and Tendon. In: Skeletal Tissue Mechanics. Springer, New York, NY. 
33.ANTONIAC, I.V.; LAPTOIU, D.; TECU, C.; MILEA, C.; GRADINARU, S. Synthetic materials for osteochondral tissue engineering, Osteochondral Tissue Engineering: Nanotechnology, Scaffolding-Related Developments And Translation, 1058 (2018), pp. 31-52

34.***ASM Aerospace Specification Metals Inc. Available online: http://asm.matweb.com/search/ SpecificMaterial.asp?bassnum=MTU030 (Accessed on 22.10. 2018)

35.BOYER, R.; WELSCH, G.; COLLINGS, E.W. Materials Properties Handbook: Titanium Alloys, ASM International, Materials Park, OH, 1994; pp. 1169, 978-0-87170-481-8.

36.PAL, S. (2014) Mechanical Properties of Biological Materials. In: Design of Artificial Human Joints \& Organs. Springer, Boston, MA.

Manuscript received: 28.03 .2020 